\title{
Assessment of an Underground Fire and the Emergency Plan
}

\author{
Marc Bascompta, Adrián Solorzano, Lluís Sanmiquel, Josep Oliva, Eduard Guasch \\ Polytechnic University of Catalonia \\ Av. Bases de Manresa 61-73, Manresa, Spain \\ marc.bascompta@upc.edu; 1luis.sanmiquel@upc.edu; josep@emrn.upc.edu; hernan.anticoi@upc.edu; \\ eduard.guasch@upc.edu
}

\section{Extended Abstract}

One of the more dangerous hazards in an underground mine is the generation of a fire due to the potential consequences to the miners. A mine fire can occur at any time, producing partial or total evacuation of mine workers. Therefore, it is crucial to determine the behaviour of the fires depending on the source fuel and the characteristics of the mine. Early detection, warning systems and preparedness are very important in this regard.

This study tries to deal with the preparedness of miners. The emergency plan has been evaluated using the software VentSim to validate the adequacy of the plan, find out weaknesses of the current system and possible alternatives. The most effective evacuation routes in terms of distance to the safe zone have been determined as well as the location of the rescue facilities inside the mine.

\section{References}

[1] B. Prosser, R. Ruckman, "Conducting a fire modeling study," 13th United States/North American Mine Ventilation Symposium, pp. 365-370, 2010. 